\title{
Association of Particulate Matter With ENT Diseases
}

\author{
Ji-Hun Mo (D) \\ Department of Otorhinolaryngology and Beckman Laser Institute Korea, Dankook University College of Medicine, Cheonan, Korea
}

Air pollution especially particulate matter is a really huge problem in East Asian countries including Korea these days. Different from sand dust (yellow dust) which is prevalent in spring season, particulate matter concentration has increased irrespective of season, and checking particulate matter concentration becomes a daily routine like checking weather forecast.

Particulate matter is a kind of air pollutant and is almost invisible fine particles that causes a lot of harmful damages to our body including respiratory system. Particulate matter is classified into PM10 (less than $10 \mu \mathrm{m}$ ), and PM2.5 (less than $2.5 \mu \mathrm{m}$ ) according to its diameter. The smaller PM2.5 can be reached into the lower airway and can cause damages into lower respiratory illness. Recently it is well known that particulate matter is absorbed in blood stream and causes many health-related problems systemically. World Health Organization published an air quality guideline for Europe in 1987 and defined particulate matter as a carcinogen on its own.

Particulate matter usually enters into our body through nasal airway. Nose is the most important passage of the air and plays an important role of air filtration and humidification. Particles more than $10 \mu \mathrm{m}$ can be filtered by the filtration capability of the nose. Nasal mucosa is covered with the sticky mucous blanket and cilia, and they cooperate with each other to filter inhaled particles. However, smaller particles less than $2.5 \mu \mathrm{m}$ cannot be filtered and go down to the lower airway.

Persistent exposure of the particulate matter can irritate the mucosa and result in initiation and/or aggravation of the inflammation. Exposure of the particulate matter on nasal airway can result in disruption of epithelial barrier function, inflammation and swelling of the nasal cavity, causing initiation and/or aggravation of the disease such as allergic rhinitis and rhinosinusitis.

Recent study revealed association of PM10 with allergic rhinitis, especially pollen allergic rhinitis [1]. Another cohort study showed that pediatric allergic rhinitis was associated with PM2.5 [2]. In case of chronic rhinosinusitis (CRS), some studies claimed association of particulate matter with CRS. One study showed that PM2.5 was significantly associated with undergoing functional endoscopic sinus surgery [3]. For each unit increase in PM2.5, there was a 1.89-fold increased risk in the proportion of chronic rhinosinusitis with nasal polyp patients who required further surgery. The effects of chronic airborne exposure of particulate matter on mice have been reported. When mice were exposed to chronic PM2.5 exposure, airway epithelial cells were disrupted with inflammatory cells infiltration and inflammatory cytokine increase [4]. Several other studies have shown that PM2.5 exposure can disrupt epithelial barrier function in vitro $[5,6]$.

In this issue of Clinical and Experimental Otorhinolaryngology, Park et al. [7] studied the association of air pollutant with ENT diseases and revealed that PM10 particles were associated with increased the risk of CRS and septal deviation using Korea National Health and Nutrition Examination Survey data. An increase in the PM10 level by $1 \mu \mathrm{g} / \mathrm{m}^{3}$ was associated with a $1.22 \%$ and a $1.43 \%$ increased risk of CRS and septal deviation, respectively. This is an interesting epidemiologic study data that can explain the relationship of air pollutants with important rhinologic diseases such as CRS and septal deviation. It is reasonable to think that PM10 can aggravate the inflammation the sinonasal cavity by disrupting epithelial integrity in case of CRS; however, more explanation and studies are needed to think of PM10 as a contributing factor of septal deviation although there was statistically significant association in this study. Several new evidences have been published to prove the harmful effects of particulate matter on upper airway diseases and more attentions need to be paid on particulate matter issues.

\section{CONFLICT OF INTEREST}

No potential conflict of interest relevant to this article was reported.

Copyright (C) 2019 by Korean Society of Otorhinolaryngology-Head and Neck Surgery.

This is an open-access article distributed under the terms of the Creative Commons Attribution Non-Commercial License (http://creativecommons.org/licenses/by-nc/4.0)

which permits unrestricted non-commercial use, distribution, and reproduction in any medium, provided the original work is properly cited. 


\section{ACKNOWLEDGMENTS}

This research was supported by the Basic Science Research Program through the National Research Foundation of Korea (NRF) funded by the Ministry of Science, ICT and Future Planning (NRF-2016R1A2B4010407).

\section{ORCID}

Ji-Hun Mo https://orcid.org/0000-0003-1331-364X

\section{REFERENCES}

1. Penard-Morand C, Raherison C, Charpin D, Kopferschmitt C, Lavaud $\mathrm{F}$, Caillaud D, et al. Long-term exposure to close-proximity air pollution and asthma and allergies in urban children. Eur Respir J. 2010 Jul;36(1):33-40.

2. Fuertes E, Brauer M, MacIntyre E, Bauer M, BellanderT, von Berg A, et al. Childhood allergic rhinitis, traffic-related air pollution, and variability in the GSTP1, TNF, TLR2, and TLR4 genes: results from
theTAG Study. J Allergy Clin Immunol. 2013 Aug;132(2):342-52.e2. 3. Mady LJ, Schwarzbach HL, Moore JA, Boudreau RM, Tripathy S, Kinnee E, et al. Air pollutants may be environmental risk factors in chronic rhinosinusitis disease progression. Int Forum Allergy Rhinol. 2018 Mar;8(3):377-84.

4. Ramanathan M Jr, London NR Jr, Tharakan A, Surya N, Sussan TE, Rao X, et al.Airborne particulate matter induces nonallergic eosinophilic sinonasal inflammation in mice. Am J Respir Cell Mol Biol. 2017 Jul;57(1):59-65.

5. Zhao R, Guo Z, Zhang R, Deng C, Xu J, Dong W, et al. Nasal epithelial barrier disruption by particulate matter $\leq 2.5 \mu \mathrm{m}$ via tight junction protein degradation. J Appl Toxicol. 2018 May;38(5):678-87.

6. London NR Jr, Tharakan A, Rule AM, Lane AP, Biswal S, Ramanathan M Jr. Air pollutant-mediated disruption of sinonasal epithelial cell barrier function is reversed by activation of the Nrf2 pathway. $\mathrm{J}$ Allergy Clin Immunol. 2016 Dec;138(6):1736-8.e4.

7. Park M, Lee JS, Park MK. The effects of air pollutants on the prevalence of common ear, nose, and throat diseases in South Korea: a national population-based study. Clin Exp Otorhinolaryngol. 2019 Aug;12(3):294-300. 